\title{
Silindirik Dielektrik Çubuğa Ait Kılavuzlanmış Modları ve Modların Adlandırılması
}

\author{
Ersoy Kelebekler \\ Kocaeli Üniversitesi, Uzunçiftlik Nuh Çimento MYO, Elektrik ve Enerji Bölümü, Kocaeli, Türkiye (ORCID: 000000029407 3926), ersoy@kocaeli.edu.tr,
}

(International Conference on Design, Research and Development (RDCONF) 2021 - 15-18 December 2021)

(DOI: 10.31590/ejosat.1039317)

\begin{abstract}
ATIF/REFERENCE: Kelebekler, E., (2021). Silindirik Dielektrik Çubuğa Ait Kılavuzlanmış Modları ve Modların Adlandirılmas1. Avrupa Bilim ve Teknoloji Dergisi, (32), 431-437.
\end{abstract}

$\ddot{O} z$

Açık bir dalga kılavuzu yapısı iletken olmayan sınır koşulları nedeniyle, tüm manyetik ve elektrik alan bileşenleri sınır içinde ve kılavuzun dışında var olurlar. Bunun sonucu olarak açık dalga kılavuzu yapılarında kapalı dalga kılavuzlarında var olan TE ve TM modaları ile birlikte HE ve EH olarak adlandırılan hibrit modlar da var olurlar. Hibrit modlar, yapıya ait karakteristik eşitlikler siteminin veya bu sitemden üretilen bir kapalı fonksiyonun farklı köklerine karşı düşmeleri nedeniyle hangisinin HE ve hangisinin EH olarak adlandırılacağı cevaplanması gereken bir sorudur. Hibrit modların adlandırılmasında elektrik alanın boyuna bileşeninin göreceli katkısını veya manyetik alanın boyuna bileşeninin göreceli katkısını temel evrensel bir yaklaşım kabul görmüştür. Bu çalışmanın amacı modların adlandırılmasında kullanılan yöntemleri sunmak ve silindirik dielektrik çubuk dalga kılavuzuna ait kılavuzlanmış TE modlarını, TM modlarını ve hibrit modları elde etmektir. Yapıya ait hibrit modların adlandırılmasında kullanılan yöntem için sayısal sonuçlar elde edilerek şekiller üzerinde sunulmuştur. İlgili şekiller üzerinde hibrit modlar arasında işaret farklılığı olduğu gösterilmiştir. Sayısal hesaplamalar sonucu evrensel olarak EH11 modu olarak kabul edilen en düşük dereceli mod ile aynı işarete sahip tüm modlar HE olarak adlandırılmıştır. Tersi olarak da ilgili mod ile zit işaretli olan tüm modlar ise EH olarak adlandırılmıştır.

Anahtar Kelimeler: Silindirik Dielektrik Çubuk, Kılavuzlanmış Modlar, Modların Adlandırılması.

\section{Guided Modes of Cylindrical Dielectric Rod and Designation of Modes}

\begin{abstract}
Due to nonconducting boundary condition of an open waveguide structure, all magnetic and electric field components exist both inside and outside the waveguide. As a result, hybrid modes called HE and EH exist in open waveguide structures, along with the TE and TM modes that exist in closed waveguides. The question has to be answered which one is designed HE and EH because hybrid modes correspond to different roots of the characteristic system of equations belonging to the structure or a closed function produced from this system. A universal approach, based on the relative contribution of the longitudinal component of the electric field or the relative contribution of the longitudinal component of the magnetic field, has been accepted to designate the hybrid modes. The aim of this study is to present the methods used in designation the modes and to obtain guided TE modes, TM modes and hybrid modes of cylindrical dielectric rod waveguide. Numerical results obtained for the method used in designation the hybrid modes of the structure presented on the figures. It is shown that there is a difference in sign between the hybrid modes on the figures. As a result of numerical calculations, all modes that have the same sign as the lowest-order mode, which is universally accepted as the EH11 mode, are named HE. Conversely, all modes with the opposite sign of the same mode are called EH.
\end{abstract}

Keywords: Cylindrical Dielectric Rod, Guieded Modes, Designation of Modes

*Sorumlu Yazar: ersoy@,kocaeli.edu.tr 


\section{Giriş}

Açık bir ortamda veya uzayda serbest uzay yayılımı, kırınım ve saçılma dişında, mikrodalga enerjisi genellikle, temel olarak bir yayılma sabiti ve iletim kaybı ile karakterize edilen yayılma davranışına sahip özel olarak tasarlanmış kılavuzlanmış dalga (guided-wave) yapıları aracılığıyla aktarılır. Kılavuzlanmış dalga yapıları, radio frekansı $(\mathrm{RF})$ ve mikrodalga devrelerinin tasarımı ve ilgili sistemlerinin geliştirilmesi noktasında temel bir birleşendir. Düzlemsel veya düzlemsel olmayan, periyodik veya düz olsun, sinyal yayılımını ve işlemeyi desteklemek için metalik ve/veya dielektrik kompozit yapı taşlarından oluşan bir kılavuzlanmış dalga yapısı kullanılır (Xu \& Wu, 2013). Son yıllarda, dielektrik dalga kılavuzu yapıları milimetrik dalga ve optik dalga teknolojisi uygulamalarında metalik dalga kılavuzuna göre daha fazla dikkat çekmektedir. Silindirik dielektrik çubuk dalga kılavuzu, dielektrik çubuk osilatörler, dielektrik resanatörler ve dielektrik resanatör antenler bu yapıların uygulamadaki bazı örnekleridir. Yüksek band genişliğine sahip iletişim hatlarında kullanılan optik fiberler ve süper hızlı bilgisayarlarda kullanılan entegre optik devreler de temelde birer dielektrik dalga k1lavuzudur (C. Yeh \& Shimabukuro, 2008). Dielektrik dalga kılavuzu yapıları mikrodalga enerjiyi istenen doğrultuda yönlendirebilme kabiliyetine sahip iken aynı zamanda mikrodalga enerjinin kılavuz dışına sızması nedeniyle anten mühendisliğinde sızıntı anten uygulamalarına imkan vermektedirler. Açık dalga kılavuzlarında kılavuz dışına sızan bu mikrodalga enerji sızıntı dalgası olarak adlandırılır. Dielektrik çubuk metalik sınıra sahip olmayan açık yapısı nedeniyle elektromanyetik yayılımın eksenel yönde gerçekleştiği bir dalga antenine benzer bu yapılar mikrodalga enerjinin kılavuz dışına uzak mesafelere yayılmasına imkan verir. $\mathrm{Bu}$ yapıların 1şıma karakteristikleri yapının boyutuna ve geometrisine, kullanılan dielektrik malzemenin elektromanyetik özelliklerine ve çalışma frekansına bağlıdır(Hirani, Pathak, Shah, \& Sharma, 2018). Sızıntı dalga yapılarının basit yapısı, maliyet etkinliği, kolay üretimi, yüksek yönlülüğü, oldukça dar desen bant genişliği ve milimetre dalga frekansından optik frekansa uygulanabilirliği gibi avantajları, onları son birkaç on yıl içerisinde popüler araştırma konuları haline getirdi (Kelebekler, 2021b).

Geçtiğimiz birkaç on yılda, hem yarı iletkenlerden hem de camdan oldukça karmaşık optik dalga kılavuzları yapmak mümkün hale gelmiştir ve sonuç olarak optik dalga kılavuzu çalışmaları büyük bir gelişim göstermiştir ( $\mathrm{Hu} \&$ Menyuk, 2009). $30 \mathrm{GHz}$ 'in altındaki frekanslar için çoğunlukla metal bazlı yapılar kullanılır ve 30 GHz'in üzerindeki frekanslar için metalde artan deri derinliği kayıpları, herhangi bir metalik malzeme kullanılmadan düşük kayıplı yapıların yapılmasını gerektirir. Bu nedenle, büyük bant genişliği sinyallerini taşımak için saf dielektrik dalga kılavuzlarının önemi ortaya çıkar. Gelişen teknoloji ile elektronik entegre devrelerle uyumlu, yüksek veri hızlı optik entegre devrelerin arayışı, silikon tabanlı optik entegre devrelerin, kaynakların, modülatörlerin ve dedektörlerin geliştirilmesinde başarılı olmuştur. Bununla birlikte terahertz bandında ki spektral bölge için optik entegre devreleri araştırmaları devam etmektedir. $\mathrm{Bu}$ spektrumdaki yüksek metalik malzeme kaybı nedeniyle, dielektrik dalga kılavuzlarının terahertz bağlantıları için tek geçerli seçenek olabileceği öngörülmektedir. İletken duvar kayıplarına sahip metalik dalga kılavuzlarına kıyasla yüksek frekansta malzeme kaybına sahip dieletrik dalga kılavuzları çok daha düşük zayıflatmaya sahiptir fakat terahertz bölgesinde arzu edilen ölçüde düşük kayıplı malzemeler henüz bulunamamıştır. Terahertz spektrumunda uygun düşük kayıplı malzemenin bulunamaması durumunda, bu spektrumdaki yüksek metalik malzeme kaybı nedeniyle kullanılamayan metalik dalga kılavuzlarına benzer şekilde, düşük kayıplı bir terahertz dalga kılavuzu tasarlamak için geleneksel optik fiber yaklaşımının kullanılamayacağı anlamına gelecektir (C. Yeh \& Shimabukuro, 2008).

Açık dalga kılavuzlarının mikrodalga enerjiyi hem kılavuzlayan hem de sızıntı şeklinde enine yönde yayılmasına imkan veren yapıları nedeniyle, yüksek frekanslı entegre devrelerde k1lavuzlama amaciyla kullanılırken farkl uygulamalarda sızıntı anteni olarak kullanılmaktadırlar. Bu iki uygulama alanı birbirinin tam olarak tersi amaçlara hizmet ettiğinden yapının hangi frekans aralığında kılavuzlama ve hangi frekans aralığında ışıma yaptığı tasarım aşamasında belirlenmelidir. Çünkü entegre devrelerde kılavuzlanan mikrodalga enerjinin k1lavuzdan sızmaması istenirken, anten uygulamalarında yüksek ışıma verimliliği istenir (Zeng, Xu, Wu, \& Luk, 2002). Açık dalga kılavuzu yapılarının davranışları genel olarak dört farklı frekans bölgesinde incelenir; gelen enerjinin hatta geri yansıtıldığı reaktif mod bölgesi, belirli bir kesim frekansı üzerinde mikrodalga enerjisinin kılavuzlandığ kılavuzlanmış mod bölgesi, kılavuzlanmış modun kılavuzlama yönünde yayılırken açık yapının yüzeyi boyunca küçük bir zayıflama ile güç sızdırdığı yüzey dalga modu bölgesi ve kılavuzun dışına enine yönde büyük bir mikrodalga enerjinin yayıldığı anten modu bölgesi (Lin, Sheen, \& Tzuang, 1996). İlgili frekans bölgelerinin sınırları, yapının geometrisi ve kullanılan malzemelerin elektromanyetik özellikleri kullanılarak Maxwell denklemlerinin analitik veya sayısal çözümlerinden elde edilir. Silindirik dielektrik çubuğa ait ilgili bölgeler Enine Elektrik (Transverse Elektrik-TE) ve Enine Manyetik (Transverse Magnetic-TM) modları için (Kim, Tae, \& Lee, 2005) çalışmasında Hibrit Elektromanyetik (Hybrid Electromagnetic-HEM) modlar için (Kelebekler, 2021b, 2021a) çalışmalarında elde edilmiştir.

Dalga k1lavuzlarında var olan modlar ve bu modların adlandırılması kılavuz yapısının açık veya kapalı olmasına bağlı olarak farklılık göstermektedir. Kapalı dalga kılavuzlarında metalik cidardaki sınır koşulları nedeniyle elektrik alanın boyuna birleşeninin sıfıra eşit olduğu $\left(E_{z}=0\right) \mathrm{TE}$, manyetik alanın boyuna birleşeninin sıfıra eşit olduğu $\left(H_{z}=0\right)$ TM ve hem elektrik hem de manyetik alanların boyuna birleşenlerinin sıfıra eşit olduğu Enine Elektromanyetik (TEM) modları var olabilir. Modların adlandırılmasında genel gösterim bu olmakla birlikte İngiliz kaynaklarında bu modlar TE ve TM için sırasıyla $\mathrm{H}$ modları ve E modları olarak kullanılabilmektedir. Dielektrik çubuk veya optik fibelerin iletken olmayan sınır koşulları nedeniyle, tüm elektrik ve manyetik alan bileşenleri sınır içinde ve dışında var olurlar. Sonuç olarak ortaya çıkan mod yapısı son derece karmaşık hale gelir ve kılavuz uzunluğu boyunca istenen kılavuzlanmış modlar ile birlikte başka yerlerde istenmeyen anten modları, yüzey modları ve reaktif modlar var olurlar (Chai Yeh, 1987). Açık dalga kılavuzlarında, kapalı dalga kılavuzlarında var olan TE ve TM modlarının ile birlikte boyuna elektrik alanın $\left(E_{z}\right)$ katkısının fazla olduğu Hibrit Elektrik (EH) modları ve boyuna manyetik alanın $\left(H_{z}\right)$ katkısının fazla olduğu 
Hibrit Manyetik (HE) modları var olabilirler. Bu modalar genel olarak HEM modları olarak sınıflandırılır. Boyuna birleşenlerin göreceli katkılarına dayanan bu yaklaşım 1949'da R.E. Beam tarafından önerilmiştir. Bu adlandırma, modların melez doğasını vurgulamak için uygun bir sınıflandırmadır (Bruno \& Bridges, 1988). 1961'de Snitzer, ikinci dereceden formdaki dairesel bir dielektrik çubuğun karakteristik denkleminin her bir kökünün ayrı bir $\mathrm{EH}$ ve HE modları grubuna karşılık geldiğini göstermiştir (Snitzer, 1961). Beam ve Snitzer tarafından yapılan mod sınıflandırması için elde edilen sonuçlar birbiriyle uyumludur. Her iki çalışma da evrensel olarak kabul edilen temel $\mathrm{HE}_{11}$ modunu temel aldımıştır ve temel moda bağlı olarak diğer hibrit modları belirlemişlerdir. Daha sonra, boyuna bileşenlerin göreceli katkısına dayanan bu yaklaşım üç katmanlı açık silindirik dalga kılavuzu (Lahart, 1998) ve fiber optik yapılar (Morishita, 1983) için de modalrın adlandırılması amacıyla kullanılmıştır.

Silindirik dielektrik çubuk dalga kılavuzuna ait TE, TM ve HE modları Davidenko metodu kullanılarak dielektrik geçirgenliği $\varepsilon_{r}=5$ ve yarıçapı $a=5$ olan yapı için (Kelebekler, 2021b) çalışmasında elde edilmiştir. Farklı yarıçap değerlerine ve dielektrik geçirgenliğe sahip silindirik dielektrik çubuk için TE, TM ve EH modları (Kelebekler, 2021a) çalışmasında elde edilerek parametrik değerlerin yapıdan enine yönde yayılımın meydana geldiği anten mod bölgesine ve mikrodalga enerjinin kılavuzlandığı kılavuzlanmış mod bölgesi için kesim frekansına etkisi sunulmuştur. Bu çalışmada silindirik dielektrik çubuk dalga kılavuzuna ait hibrit modların adlandırılmasında kullanılan boyuna elektriksel ve boyuna manyetik alanların göreceli katkılarına dayanan, ayrıca, [4] ve [9] çalışmalarında modların adlandırılmasında kullanılan yaklaşım için ayrıntılı sayısal çözümler sunulacaktır. Böylece ilgili çalışmalarda kullanılan adlandırmaların geçerliliği gösterilecektir.

\section{Kapalı ve Açık Dalga Kılavuzu Yapılarına Genel Bakış}

Elektromanyetik dalga k1lavuzları, üç boyutlu uzayda her yöne yayılma eğiliminde olan elektromanyetik enerjiyi istenilen doğrultuda yönlendirmeye yarayan yapılardır. Genel olarak elektromanyetik dalga kılavuzları, kapalı dalga kılavuzları ve açık dalga kılavuzları olarak iki sınıfa ayrılabilir.

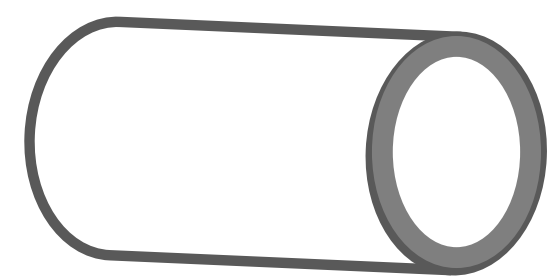

(a)

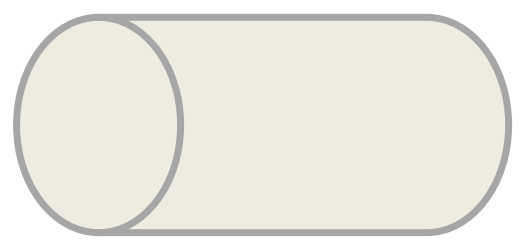

(b)

Şekil 1. Elektromanyetik dalga kılavuzları: (a) kapalı dalga kılavuzu, (b) açık dalga kılavuzu (dielektrik çubuk)
Şekil 1 (a)’ da görüldüğü gibi kapalı dalga kılavuzları en dışta cidar olarak adlandırılan iletken bir sınıra sahiptir ve bu yüzden metalik dalga kılavuzu olarak da adlandırılırlar. İç ve dış bölgelerin metalik duvarlar tarafindan sinırlandırıldığ bölgelerin çevreleyen ortamdan mükemmel bir şekilde izole edildiği kapalı dalga kılavuzlarının örnekleri olarak uygulamada sıklıkla kullanılan koaksiyel kablolar ve klasik metalik dalga kılavuzları gösterilebilir. Metalik dalga kılavuzları dikdörtgensel, silindirik veya eliptik yapılarda olabilir. Her bir geometrik yapının çözüm eşitlikleri farklı dik fonksiyonlar kümelerinin elemanlarını içerirler. Örneğin dikdörtgensel dalga kılavuzu çözüm eşitlikleri sinüs ve kosinüs fonksiyonlarından oluşurken silindirik yapıların çözüm eşitlikleri Bessel fonksiyonlarından oluşmaktadır.

Şekil 1 (b)'de verilen dielektrik çubuk gibi yapılar ise iletken bir sınıra sahip olmadıkları ve elektromanyetik enerjinin enine bir yönde yayılmasına izin verdikleri için açık dalga kılavuzları olarak adlandırılırlar. Fiber optik kablolar açık dalga kılavuzları sınıfının uygulamada kullanılan en önemli örnekleridir. Bununla birlikte dielektrik çubuk dalga kılavuzları, mikro şerit yapılar, gömülü mikro şerit dalga kılavuzları, mikro şerit hatlar, yarık hatlar, eş düzlemli dalga kılavuzları gibi yapılar açık dalga kılavuzu yapıları örnekleridir. Bu çalışmada silindirik dielektrik çubuk dalga kılavuzu yapısı incelenmektedir.

\section{Silindirik Dielektrik Çubuk Dalga Kılavuzu}

Elektromanyetik dalgaların, sonsuz ve homojen bir dielektrik ortama gömülmüş sonsuz uzunlukta ideal bir dielektrik dairesel silindir boyunca yayılması, geçen yüzyılın başından beri klasik bir problem olmuştur. $\mathrm{Bu}$ probleme uygulanan silindirik koordinat sistemindeki dalga denklemlerinin çözümleri, bu tip bir dalga kılavuzunun alan yapısının, içi boş metalik dalga kılavuzundan çok daha karmaşık olduğunu ortaya çıkartmıştır [5]. Metalik dalga kılavuzlarında kılavuzlanmış modlar kolaylıkla TE, TM ve hatta TEM modları olarak sinıflandırılabilir. Bir optik fiberin iletken olmayan sınır koşulu nedeniyle, tüm elektrik ve manyetik alan bileşenleri sınır içinde ve dışında bulunur. Ortaya çıkan mod yapısı son derece karmaşık hale gelir. Bu yapılarda farklı frekans bölgelerinde, kılavuz uzunluğu boyunca ilerlemesi istenen kılavuzlanmış dalga mod bölgeleri ve yüzey dalgası mod bölgeleri, kılavuz dışına enine yönde yayılan anten modu bölgeleri ve hatta geri yansıyan reaktif mod bölgeleri var olurlar. Elektromanyetik dalganın davranışına göre sınıflanan bölgeler için analitik çözüm kümelerine bağlı olarak elde edilen çözümler TE, TM ve HEM modları olarak adlandırılır. İlgili modlara ait çözüm eşitlikleri çalışma içerisinde sunulacaktır.

$\mathrm{Bu}$ çalışmanın temel amacı silindirik dalga kılavuzu modlarının adlandırılmasında temel alınan yaklaşımı açıklamak, özellikle açık dalga kılavuzu yapılarında sınır koşulları ve mikrodalga enerjinin kılavuz dışına enine yönde yayılması nedeniyle var olan HEM modlarının adlandırılmasında kullanılan boyuna alan bileşeninin göreceli katkısına dayanan yaklaşımı kullanarak $\mathrm{HE}$ ve $\mathrm{EH}$ modlarını saptamaktır. $\mathrm{Bu}$ bölümde silindirik dielektrik çubuğa ait TE, TM ve HEM modları için analitik çözümler verilecek ve HEM modlarının sınıflandırılması noktasında kullanılacak yaklaşımın temel analitik ifadeleri sunulacaktır. Silindirik koordinat sistemi 
değişkenleri $r, \varphi, z$ ve açısal frekans $\omega$ olmak üzere yapı için alanların değişimi Eşitlik (1)'de verilmiştir.

$$
F(r, \varphi, z)=F(r) e^{j(\omega t-\gamma z-m \varphi)}
$$

Burada, $\gamma$ kompleks yayılım sabiti ve m azimutal değişimi göstermektedir. Silindirik dielektrik çubuk için yalın TE ve TM modları sadece açısal değişimden $(\varphi)$ bağımsız simetrik alan konfigürasyonunda var olurlar. Diğer bir deyişle, bu modlar azimutal değişimin $(m=0)$ sıfır ve sırasıyla TE modu için elektrik alanın $\left(E_{z}=0\right)$ boyuna bileşeninin sıfır, TM modu için manyetik alanın boyuna bileşeninin sıfır alınarak analitik çözümlerden elde edilen cebirsel denklemlerin sayısal çözümlerinden elde edilir. Ayrıca bu modlar $\mathrm{TE}_{0 \mathrm{n}}$ veya $\mathrm{TM}_{0 \mathrm{n}}$ olarak numaralandırılır. Alt indisteki sıfır azimutal değişimi ve $n$ $(\mathrm{n}=1,2, \ldots)$ ise artan frekansa bağlı mod sırasını göstermektedir. Bununla birlikte, bir mod için açısal $(\varphi)$ değişim mevcut ise mod yalın TE veya TM modu olamaz. Bu azimutal değişimin sıfırdan farklı olması $(m \neq 0)$ anlamına gelir. Sonuç olarak, TE ve TM modlarının birleşimi olan alan konfigürasyonu simetrik olmaz ve açısal değişime sahiptir. Genel kullanımda hibrit modlar olarak tanımlanan bu modlar HEM modları olarak adlandırılır (Balanis, 1989). Ayrıca HEM modları boyuna alan bileşenin göreceli katkısına göre $H_{m n}$ veya $\mathrm{EH}_{\mathrm{mn}}$ olarak adlandırılır. Alt indisler sırasıyla azimutal değişimi ve artan frekansa bağlı mod sırasını göstermektedir. HEM modlarını, TE ve TM modlarından ayıran temel nokta hem $\mathrm{HE}$ hem de $\mathrm{EH}$ modlarının aynı cebirsel denklemler takımından elde edilmesidir. Dolayısıyla analitik denklemler takımının hangi kökünün $\mathrm{HE}$ moduna ve hangi kökünün $\mathrm{EH}$ moduna karşı düştüğü cevaplanması gereken bir sorudur. Bu çalışmada ilk R.E. Beam tarafindan önerilen ve sonrasında pek çok çalışmada referans alınan boyuna alanın göreceli katkısına dayanan yaklaşım kullanılarak ilgili modların adlandırması yapılacaktır. Çalışmada öncelikle silindirik dielektrik çubuk yapısına ait TE, TM ve HEM modları için analitik çözüm eşitlikleri sunulacaktır.

Kılavuzlanmış mod bölgesi, dalga kılavuzu boyunca mikrodalga enerjinin kılavuzlandığı frekans aralığında frekansyayılım sabiti ilişkisini gösterir. Dispersiyon (dağılım) eğrileri olarak da adlandırılan bu karakteristik eğriler, Maxwell Eşitlikleri, yapının elektriksel özellikleri ve sınır koşulları kullanılarak elde edilen karakteristik eşitlikler siteminden veya bu eşitliklerin kapalı formu olan dispersiyon eşitliğinden elde edilir. Dielektrik geçirgenliği $\varepsilon_{r}$ ve yarıçapı $a$ olmak üzere silindirik dielektrik çubuğa ait TE, TM ve HEM modları için karakteristik eşitlikler sistemleri sırasıyla (2), (3) ve (4) eşitliklerinde sunulmuştur. TE modları ve TM modları azimutal değişimin sıfır $(m=0)$ iken sırasıyla, elektrik alanın boyuna bileşeninin sıfır $\left(E_{z}=0\right)$ alınarak ve manyetik alanın boyuna birleşeninin sıfır $\left(H_{z}=0\right)$ alınarak elde edilen çözüm takımlarıdır. HEM modları ise azimutal değişim sıfırdan faklı $(m \neq 0)$ iken hem elektrik alanın boyuna hem de manyetik alanın boyuna bileşenlerinin sıfırdan farklı olduğu çözüm takımlarından oluşur.

$$
\begin{gathered}
{\left[\begin{array}{cc}
J & -K \\
a_{1} J^{\prime} & a_{2} K^{\prime}
\end{array}\right]\left[\begin{array}{l}
B \\
D
\end{array}\right]=0} \\
{\left[\begin{array}{cc}
J & -K \\
b_{1} \varepsilon_{r} J^{\prime} & b_{2} K^{\prime}
\end{array}\right]\left[\begin{array}{l}
A \\
C
\end{array}\right]=0}
\end{gathered}
$$

$$
\left[\begin{array}{cccc}
c_{1} J & d_{1} J^{\prime} & c_{2} K & d_{2} K^{\prime} \\
0 & J & 0 & -K \\
-\frac{d_{1} \varepsilon_{0} \varepsilon_{r}}{\mu_{0}} J^{\prime} & c_{1} J & -\frac{d_{2} \varepsilon_{0}}{\mu_{0}} K^{\prime} & c_{2} K \\
J & 0 & -K & 0
\end{array}\right]\left[\begin{array}{c}
A \\
B \\
C \\
D
\end{array}\right]=0
$$

Burada, $J=J_{m}\left(k_{1} a\right), K=K_{m}\left(k_{2} a\right), J^{\prime}=J^{\prime}{ }_{m}\left(k_{1} a\right), K^{\prime}=$ $K_{m}^{\prime}\left(k_{2} a\right), a_{n}=j \frac{\omega \mu_{0}}{k_{n}}, b_{n}=-j \frac{\omega \varepsilon_{0}}{k_{n}}, c_{n}=-\frac{m \gamma}{a k_{n}^{2}}, d_{n}=j \frac{k_{0}^{2}}{\omega \varepsilon_{0} k_{n}}$, ve $n=1,2 . J_{m}$ ve $K_{m}, \mathrm{~m}$. dereceden birinci tip Bessel ve ikinci tip Bessel fonksiyonlarını temsil etmektedir. Kesme işareti ise türevi temsil etmektedir. Ayrıca, $j$ sanal birim sayı, $\varepsilon_{0}$ ve $\mu_{0}$ boşluk uzayın elektriksel ve manyetik geçirgenlikleridir. $k_{0}, k_{1}$, $k_{2}$ sırasıyla boşluk ortamdaki dalga sayısı, çubuk içerisindeki dalga sayısı, çubuk dışındaki dalga sayısı olarak adlandırılır ve $k_{0}=\sqrt{\omega^{2} \varepsilon_{0} \mu_{0}}, k_{1}=\sqrt{k_{0}^{2} \epsilon_{r}-\gamma^{2}}$ ve $k_{2}=\sqrt{k_{0}^{2}-\gamma^{2}}$ şeklinde tanımlidir.

Karakteristik denklemler sisteminin katsayı matrisinin determinantının sıfırları, kapalı formdaki denkleminin sıfırlarına karşılık gelir. $\mathrm{Bu}$ durumda, $\boldsymbol{M}$ karakteristik denklemler sisteminin katsayı matrisi olmak üzere aşağıdaki ifade geçerlidir.

$$
F(\omega ; \gamma)=\operatorname{det}(\boldsymbol{M})=0
$$

Sayısal çözümlerde sabit frekans değerleri için Eşitlik (5)'i sağlayan yayılım sabiti değerleri elde edilerek TE, TM ve HEM modları için dispersiyon $(\omega-\gamma)$ eğrileri elde edilir. Çalışmada ilgili modlar sunulacak ve çalışmanın ana katkısı olarak Eşitlik (4)'ten elde edilen köklerin adlandırılmasında kullanılan yaklaşım verilecektir.

\section{Silindirik Dielektrik Çubuk Modları ve Modların Adlandırılması}

Silindirik dielektrik çubuk dalga kılavuzu, kılavuzlanmış modlar dielektrik dalga k1lavuzu içinde k1lavuz boyunca ilerleyen mikrodalga enerjiyi, anten modları kılavuzun dışında enine yönde yayılan modları ve reaktif modlar ise enerjinin besleme hattına geri yansıyan ve sönümlenen mikrodalga enerjiyi temsil etmektedir. Bunula birlikte TE, TM ve HEM modları ise yapının sınır koşullarına bağlı elde edilen analitik çözümlere bağlı olarak adlandırılırlar. Buradaki kritik nokta HEM çözümlerinden elde edilen iki farklı kökün birinin HE moduna, diğerinin ise $\mathrm{EH}$ moduna karşılık gelmelidir. $\mathrm{Bu}$ noktada hangi kökün hangi moda karşılık geldiğini belirlemek için kullanılan en geçerli yaklaşım alanların boyuna bileşenlerinin göreceli katkısını belirlemektir. $\mathrm{Bu}$ yaklaşımda ilgili mod için boyuna elektrik alan katkısı daha fazla ise mod $\mathrm{EH}$, boyuna manyetik alan katkısı daha yüksek ise mod HE olarak adlandırılmaktadır. Eşitlik (6)'da boyuna alan elektrik ve manyetik bileşenlerinin genlik oranına dayanan ifade verilmiştir (Bruno \& Bridges, 1988; Lahart, 1998; Morishita, 1983; Snitzer, 1961).

$$
P=-\frac{\omega \mu_{0}}{\beta} \frac{H_{z}}{E_{z}} \cong \frac{m\left[\frac{1}{\eta_{1}^{2}}+\frac{1}{\eta_{2}^{2}}\right]}{\frac{J^{\prime}}{\eta_{1} J}+\frac{K^{\prime}}{\eta_{2} K}}
$$


Burada, $\beta$ kompleks yayılım sabitinin reel kısmı olan faz sabitini göstermektedir ve $\eta_{n}=k_{n} a, n=1,2$ olarak tanımlıdır. Kılavuzlanmış mod bölgesi için kompleks yayılım sabiti saf reel değerler alır. Hibrit modların isimlendirilmesi, sabit bir frekans değerinde Eşitlik (6) ifadesinin aldığ 1 değere göre belirlenir. Birinci hibrit mod evrensel olarak $\mathrm{HE}_{11}$ olarak kabul edilir. İlk mod için P'nin işareti tüm HE modlarının işareti olarak kabul edilir ve zıt işaretli $\mathrm{P}$ değerlerine karşı düşen modlar ise $\mathrm{EH}$ modu olarak alınır. $\mathrm{Bu}$ yöntem evrensel olarak kabul görmüş hibrit modların doğasını doğru bir biçimde temsil eden bir yaklaşımdır.

Yarıçapı $a=5 \mathrm{~mm}$ ve dielektrik geçirgenliği $\varepsilon_{r}=5$ olan yap1 için sırasıyla Eşitlikler (2) ve (3)'ten elde edilen kılavuzlanmış TE ve TM modların ilk beşi Şekil 2'de verilmiştir.

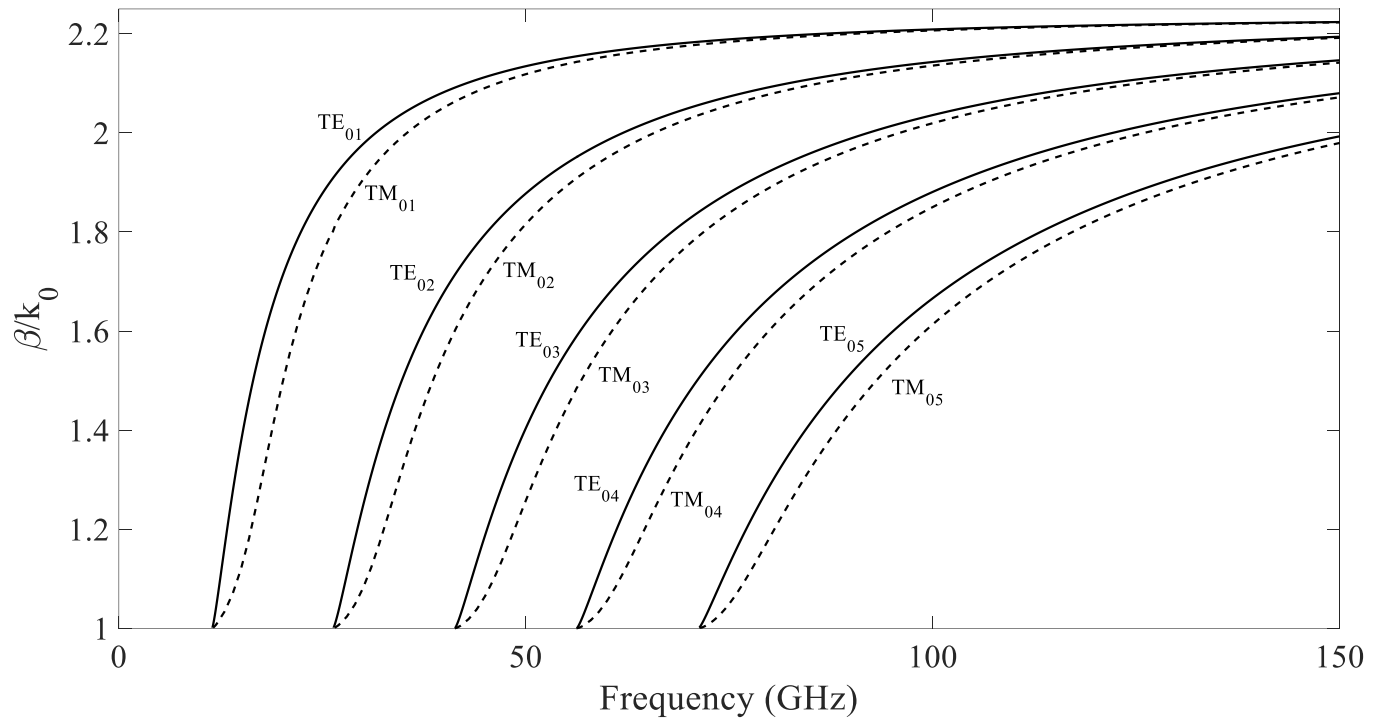

Şekil 2. Yarıçapı $a=5 \mathrm{~mm}$ ve dielektrik geçirgenliği $\varepsilon_{r}=5$ olan yapı için kılavuzlanmış TE ve TM modları

Şekilde görüldüğü gibi, eşit mod numaralı $\mathrm{TE}_{0 \mathrm{n}}$ ve $\mathrm{TM}_{0 \mathrm{n}}$ modları için kesim frekansı eşittir. Örneğin $\mathrm{TE}_{01}$ ve $\mathrm{TM}_{01}$ modları için kesim frekansı $11.47 \mathrm{GHz}$ 'e eşittir ve bu frekansın altında ilgili modun kılavuz içesinde iletilemeyeceği anlamına gelir. Kesim frekansının altında kalan anten modu frekans bölgesi veya reaktif mod frekans bölgesi gibi kılavuzlanmış mod bölgesi harici frekans bölgeleri için ayrıntılı analizler (Kelebekler, 2021b) ve (Kelebekler, 2021a) çalışmalarında sunulmuştur. Bu çalışmanın ana amacı ise Eşitlik (4)'ten elde edilen HEM modların hangisinin $\mathrm{HE}$ hangisinin $\mathrm{EH}$ olarak adlandırılacağının evrensel bir yöntem ile belirlenmesidir.

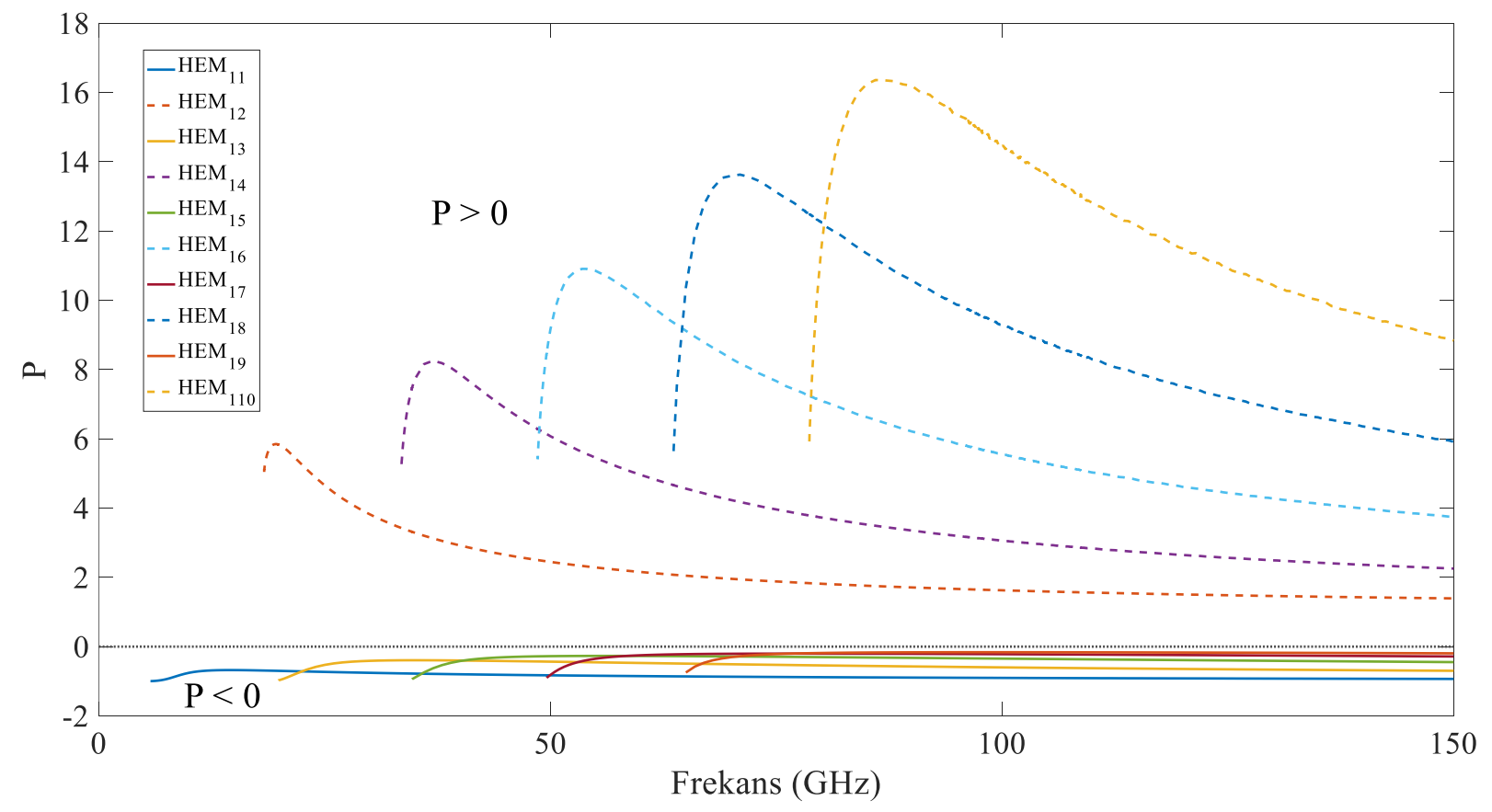

Şekil 3. Yarıçapı $a=5 \mathrm{~mm}$ ve dielektrik geçirgenliği $\varepsilon_{r}=5$ olan yapı için P'nin genliği

Örneğin $50 \mathrm{GHz}$ çalışma frekansı için Eşitlik (5)’te katsayılar matrisinin determinantını sıfır yapan farklı yedi adet yayılım sabiti değerinden en küçük değerli olanı evrensel olarak $\mathrm{HE}_{11}$ modu kabul edilir. Diğer modların adlandırılması ise 
Eşitlik (6)'daki P'nin işareti hesaplatılarak belirlenir. $\mathrm{HE}_{11}$ modu ile aynı işarete sahip yayılım sabitleri $\mathrm{HE}_{1 \mathrm{n}}$ modlarına karşı düşerken, zıt işaretliler ise $\mathrm{EH}_{1 \mathrm{n}}$ modlarına karşı düşmektedir. Azimutal değişimin bire $(m=1)$ eşit olduğu ilk on adet $\mathrm{HEM}_{1 \mathrm{n}}$ modu için frekansa göre P'nin sayısal değeri Şekil 3'te verilmiştir.

Şekilde görüldüğü üzere kesim frekansı en düşük olan $\mathrm{HEM}_{11}$ modu negatif $\mathrm{P}$ işaretine sahiptir. Evrensel şekilde $\mathrm{HE}_{11}$ modu olarak kabul edilen mod ile aynı işarete sahip $\mathrm{P}<0$ bölgesinde kalan modlar frekansa göre artan mod numaralarıyla $\mathrm{HE}_{12}, \mathrm{HE}_{13}, \mathrm{HE}_{14}$ ve $\mathrm{HE}_{15}$ olarak adlandırılacaklardır. Tersi olarak ise $\mathrm{HE}_{11}\left(\mathrm{HEM}_{11}\right)$ modu ile zit işarete sahip $\mathrm{P}>0$ bölgesinde kalan modlar frekansa göre artan mod numaralarıyla $\mathrm{EH}_{12}, \mathrm{EH}_{13}, \mathrm{EH}_{14}$ ve $\mathrm{EH}_{15}$ olarak adlandırılacaklardır. Yarıçap1 $a=5 \mathrm{~mm}$ ve dielektrik geçirgenliği $\varepsilon_{r}=5$ olan yapı için Eşitlik (4)'ten elde edilen kılavuzlanmış HEM modlarının ilk on tanesi Şekil 4'te verilmiştir. Yukarıda açıklandığı ve sayısal olarak Şekil 3 'te verildiği gibi bu modlardan beş tanesi HE modlarına, diğer beş tanesi ise EH odlarına karşı düşmektedir.

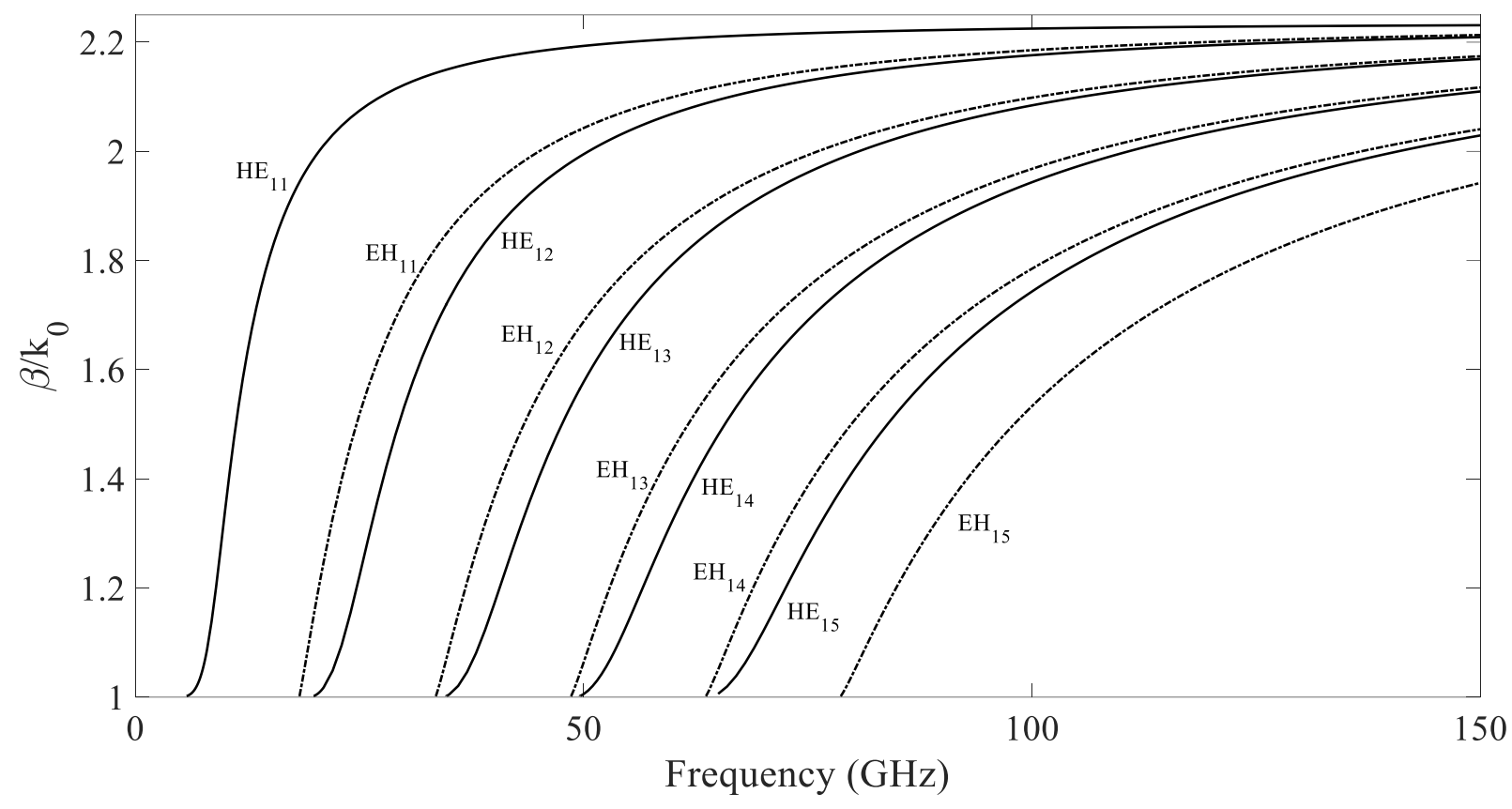

Şekil 4. Yarıçapı $a=5 \mathrm{~mm}$ ve dielektrik geçirgenliği $\varepsilon_{r}=5$ olan yapı için kılavuzlanmış HEM modları

TE ve TM modlarından farklı olarak HEM modları için EH modlarının ve HE modlarının kesim frekansı özdeş değildir. $\mathrm{HE}_{11}$ modu için kesim frekans1 $5.71 \mathrm{GHz}$ iken $\mathrm{EH}_{11}$ modu için kesim frekansı 18.3 GHz'e eşittir. Elde edilen modların literatürle uyumlu olduğu, kılavuzlanmış modların frekans bölgesi haricinde var olan anten modları frekans bölgesi ve reaktif mod bölgeleri aynı yapı için (Kelebekler, 2021b) çalışmasında sunulmuştur. Ayrıca (Kelebekler, 2021a) çalışmasında yapının farklı parametrik değerleri için ilgili bölgelerin karakteristikleri incelenmiştir. Fakat her iki çalışmada da HEM modlarının adlandırılması için kullanılan yöntem ayrıntılandırılmamıştır. $\mathrm{Bu}$ çalışmada HEM modlarının adlandırılmasında kullanılan boyuna elektrik veya boyuna manyetik alanın göreceli katkısına dayanan yaklaşım ayrıntılı olarak verilmiştir. Ayrıca sunulan modların isimlerinin geçerliliği, ilgili yaklaşıma dayanan sayısal çözümler ile gösterilmiştir.

\section{Sonuç}

Açık dalga kılavuzu yapıları kapalı dalga kılavuzu yapılarında olduğu gibi mikrodalga enerjiyi kılavuz boyunca yönlendirebilirken aynı zamanda iletken olmayan sınırları nedeniyle enerjinin enine yönde sızmasına izin veren yapılardır. İletken bir cidara sahip olmadıkları için özellikle yüksek frekansta metalik malzeme kaybı içermeyen yalnızca malzeme kaybına sahiptirler. $\mathrm{Bu}$ özellikleriyle yüksek frekanslarda k1lavuzlama amaciyla tercih edilirler. Bu yapıların elektriksel özellikleri ve sınır koşulları kullanılarak Maxwell denklemlerinden elde edilen analitik çözümler mod olarak adlandırılır ve Brillouin eğrileri olarak da adlandırılan dispersiyon eğrileri üzerinde sunulurlar. $\mathrm{Bu}$ eğriler frekans ile yayılım sabiti ilişkisini vererek yapının hangi frekans aralığında mikrodalga enerjiyi kılavuzlayacağını veya hangi frekans aralığında bir anten gibi 1şıma yapacağını gösterir. Kapalı dalga kılavuzu yapılarında TE, TM ve TEM modları var olabilirken, açık dalga kılavuzu yapılarında sınır koşulları ve mikrodalga enerjinin yapının dışına enine yönde de yayılabilmesi nedeniyle TE, TM modları ile birlikte HEM modları da var olabilirler. Azimutal değişim sıfir iken, TE modları elektrik alanın boyuna bileşeni sıfır, TM modları ise manyetik alanın boyuna bileşeni sıfır alınarak elde edilir. Açık kılavuzlarda var olabilen HEM modarı ise azimutal değişiminin sıfirdan farklı ve tüm alan bileşenlerinin mevcut olduğu durumdan elde edilir.

Çalışmada temel amaç, modların adlandırılmasını açıklamak ve hibrit modlarda var olan tek bir çözüm takımının farklı köklerine karşı farklı modların düşmesini evrensel bir koşula bağlı olarak incelemektir. TE ve TM modları ayrı birer çözüm takımından elde edilir ve frekans ile artan şekilde $\mathrm{TE}_{0 \mathrm{n}}$ ve $\mathrm{TM}_{0 \mathrm{n}}$ olarak adlandırılır. Bununla birlikte HEM modları tek bir çözüm takımından elde edilen iki farklı kökün $\mathrm{HE}$ veya $\mathrm{EH}$ olarak adlandırılması farklılığına sahiptir. Boyuna bileşenin göreceli katkısına dayanan bir şema kullanmak evrensel olarak kabul 
görmüş bir yaklaşımdır. Bu çalışmada elektrik alanın boyuna bileşeninin veya manyetik alanın boyuna bileşeninin göreceli katkısına dayanan şema için analitik ifade sunulmuştur. Elde edilen modlar bu ifade kullanılarak sayısal olarak hesaplatılmıştır. Sayısal hesaplamalar sonucu elde edilen şekiller üzerinde $\mathrm{HEM}_{1 \mathrm{n}}$ modları sunularak şematik yaklaşıma göre modlar arasında işaret farklılı̆̆ı olduğu gösterilmiştir. Bu işaret farklılıkları modların adlandırılmasında temel oluşturmaktadır. Sayisal hesaplamalar sonucu evrensel olarak $\mathrm{EH}_{11}$ modu olarak kabul edilen en düşük dereceli mod ile aynı işarete sahip tüm modlar frekans ile artan şekilde $\mathrm{HE}_{1 \mathrm{n}}$ olarak adlandırılmıştır. Tersi olarak da ilgili mod ile zıt işaretli olan tüm modlar ise frekans ile artan şekilde $\mathrm{EH}_{1 \text { n }}$ olarak adlandırılmıştır.

Açık kılavuz yapılarında var olabilen hibrit modların araştırılması başlıklarını içeren ileriki çalışmalarda tek bir denklem takımından elde edilen farklı köklerin karşı düştüğü HEM modları çalışmada sunulan yaklaşım kullanılarak adlandır1labilir.

\section{Kaynakça}

Balanis, C. A. (1989). Advanced engineering electromagnetics. Wiley.

Bruno, W. M., \& Bridges, W. B. (1988). Flexible Dielectric Waveguides with Powder Cores. IEEE Transactions on Microwave Theory and Techniques, 36(5), 882-890. https://doi.org/10.1109/22.3608

Hirani, R. R., Pathak, S. K., Shah, S. N., \& Sharma, D. K. (2018). Dispersion characteristics of dielectric tube waveguide loaded with plasma for leaky wave antenna application. AEU - International Journal of Electronics and Communications, 83, 123-130. https://doi.org/10.1016/j.aeue.2017.08.019

Hu, J., \& Menyuk, C. R. (2009). Understanding leaky modes: Slab waveguide revisited. Optics InfoBase Conference Papers, 1(1), 58-106. https://doi.org/10.1364/aop.1.000058

Kelebekler, E. (2021a). An analysis of leaky hybrid modes depending on structural parameters in a circular dielectric rod. Frequenz, 75(9), 377-387. https://doi.org/10.1515/freq2020-0189

Kelebekler, E. (2021b). Investigation of the Leaky-Wave Characteristics of a Cylindrical Dielectric Rod Using the Coefficient Matrix of the System of Characteristic Equations and Davidenko's Method. Journal of Electromagnetic Engineering and Science, 21(3), 189-200. Retrieved from http://jees.kr/journal/view.php?doi=10.26866/jees.2021.3.r.2 6

Kim, K. Y., Tae, H., \& Lee, J.-H. (2005). Leaky Dispersion Characteristics in Circular Dielectric Rod Using Davidenko's Method. Journal of the Korea Electromagnetic Engineering Society, 5(2), 72-79.

Lahart, M. J. (1998). Analysis of a cylindrical dielectric waveguide with three regions by use of an invariant modedefinition parameter. Journal of the Optical Society of $\begin{array}{lll}\text { America } & \text { A, } & \text { 15(3), }\end{array}$ https://doi.org/10.1364/josaa.15.000727

Lin, Y.-D., Sheen, J. wen, \& Tzuang, C. C. (1996). Analysis and design of feeding structures for microstrip leaky wave antenna. IEEE Transactions on Microwave Theory and Techniques, 44(9), 1540-1547.
Morishita, K. (1983). Hybrid Modes in Circular Cylindrical Optical Fibers. IEEE Transactions on Microwave Theory and Techniques, 31(4), 344-350. https://doi.org/10.1109/TMTT.1983.1131495

Snitzer, E. (1961). Cylindrical Dielectric Waveguide Modes. Journal of the Optical Society of America, 51(5), 491-498. https://doi.org/10.1364/josa.51.000491

Xu, F., \& Wu, K. (2013). Understanding Leaky-Wave Structures. IEEE Microwave Magazine, 14(5), 87-96.

Yeh, C., \& Shimabukuro, F. I. (2008). The Essence of Dielectric Waveguides. In Springer. Springer.

Yeh, Chai. (1987). Guided-Wave modes in cylindrical optical fibers. IEEE Transactions on Education, E-30(1), 43-51. https://doi.org/10.1109/TE.1987.5570585

Zeng, X. Y., Xu, S. J., Wu, K., \& Luk, K. M. (2002). Properties of guided modes on open structures near the cutoff region using a new version of complex effective dielectric constant. IEEE Transactions on Microwave Theory and Techniques, 50(5), 1417-1424. https://doi.org/10.1109/22.999157 